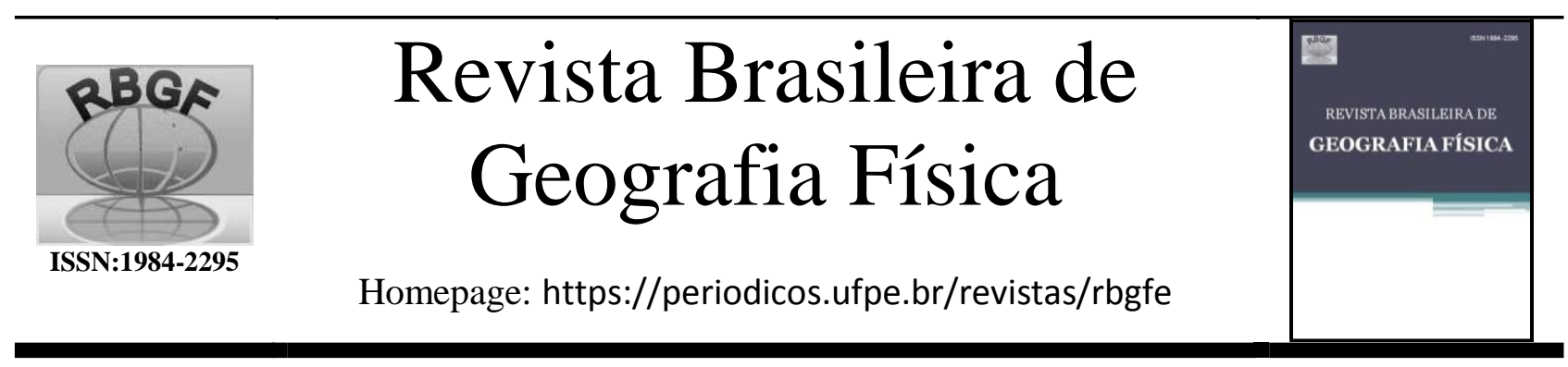

\title{
Identificação dos leques aluviais dissecados do Quadrilátero Ferrífero (MG) através de critérios espaciais e sedimentológicos
}

\author{
Fabrício Antonio Lopes ${ }^{1}$, Paulo de Tarso Amorim Castro ${ }^{2}$, Cláudio Eduardo Lana ${ }^{3}$, Renato Coelho Dias ${ }^{4}$
}

\begin{abstract}
${ }^{1}$ Doutorando em Ciências Naturais, Departamento de Geologia, Universidade Federal de Ouro Preto. Rua José Geraldo Ferreira, 149, 35960-000, Ana Margarida, Santa Bárbara, Minas Gerais, fabricioantoniolopes@gmail.com (autor correspondente). ${ }^{2}$ Professor titular do Departamento de Geologia, Universidade Federal de Ouro Preto. RuaProfessor Paulo Magalhães Gomes, s/n, 35400-000, Bauxita, Ouro Preto, Minas Gerais, ptacastro @ gmail.com ${ }^{3}$ Professor Titular, Departamento de Geologia, Unidade Federal de Ouro Preto. Rua Professor Paulo Magalhães Gomes, s/n, 35400-000, Bauxita, Ouro Preto, Minas Gerais, claudiolana @ gmail.com. ${ }^{4}$ Mestrando em Ciências Naturais, Departamento de Geologia, Universidade Federal de Ouro Preto. Rua dez, 07, 75706-120, Setor Universitário, Catalão, Goiás, renatocoelhogeo@gmail.com
\end{abstract}

Artigo recebido em 17/02/2021 e aceito em 22/05/2021

\section{R E S U M O}

O objetivo desse estudo foi identificar os depósitos de leques aluviais colmatados ao longo da base das escarpas do Quadrilátero Ferrífero. A referida identificação ocorreu primeiramente em gabinete, onde foram realizadas leituras de trabalhos relaciona dos a geomorfologia da região bem como a interpretação dos mapas geológicos disponíveis. Os da dos obtidos em gabinete serviram de base para nortea mento dos trabalhos de ca mpo, onde foi possível ana lisar carac terísticas espaciais, sedimentológicas e morfométricas dos depósitos de encosta e inferir sobre seu possível ambiente deposicional. Os trabalhos de campo foram direciona dos a cinco depósitos loca lizados nas bordas Sul, Oeste e Noroeste do Qua drilátero Ferrífero cujos sedimentos estão posicionados de forma oblíqua ao vale principal com características faciológicas que remetem a fluxos de detritos desconfinados. Nos depósitos 1 e 2 foram verifica das diminuição granulométrica de montante para jusante, indicando brusca perda de energia. Essas características somadas as elevadas espessuras dos depósitos de fluxos de detritos permitiram inferir que tais acumulações compreendem leques aluviais inativos, atualmente em fase de dissecação pelos elementos erosivos naturais e antrópicos. Ta is leques aluviais podem conter importantes informações a respeito do quadro paleoclimático e paleomorfológico da região, tendo potencial para contribuir com novos dados e aumentar o horizonte de interpretações a respeito da dinâmica paleoa mbientalquaternária regional.

Palavras-chave: Quaternário, depósitos sedimentares, fluxo de detritos, paleogeografia.

\section{Identification of alluvial fans dissected from the Quadrilátero Ferrífero (MG) through spatial and sedimentological criteria}

\begin{abstract}
A B S T R A C T
This study aims to identify deposits of alluvial fans that were filled in along the base of the Iron Quadrangle escarpments. This identification occurred first in the office, where readings of works related to the geomorphology of the region were carried out, as well as the interpretation of the available geological maps. The data obtained in the office was the basis for guiding fieldwork, through which it was possible to analyze spatial, sedimentologic and morphometric characteristics of the slope deposits and to infer their possible depositionalenvironment. The fieldwork was directed to five deposits located on the South, West and Northwest edges of the Iron Quadrangle whose sediments are plac ed obliquely to the main valley with faciologicalcharacteristics denoting unfinished debris flows. In deposits 1 and 2, there was a granulometric decrease from downstream to upstream, indicating an abrupt loss of energy. These characteristics added to the high thickness of the deposits of debris flows allowed to infer that such accumulations comprise inactive alluvial fans, currently in the dissection phase by natural and antropic erosive elements. Such alluvial fans may contain important information about the region's paleoclimatic and paleomorphological framework, with the potential of contributing with new data and increasing the range of interpretations regarding the regional quaternary paleoenvironmentaldynamics.
\end{abstract}

Keywords: Quaternary, sedimentary deposits, debris flow, paleogeography. 


\section{Introdução}

Os leques aluviais configuram depósitos de material detrítico mal selecionado provenientes das áreas altas adjacentes, que adquirem grande mobilidade lateral em função do desconfinamento do fluxo (Harvey et al., 2018; Silveira e Silveira, 2020). A referida feição sedimentar e geomorfológica pode ser originada por fluxos de natureza gravitacional e/ou por sistemas fluviais (natureza aluvial com transporte aquático) cujas características litológicas, climáticas e tectônicas regionais são os principais controladores da dinâmica atuante em sua superfície (Bull, 1968; Cable et al., 2018; Nogueira et al., 2020; Camacho et al., 2020; Welivitiya et al., 2020; Babič et al., 2021; Vasconcellos et al., 2021).

Em vasta revisão teórica Blair e McPherson (1994) elencaram características específicas de sistemas deposicionais compostos por leques aluviais, as principais são: 1) amplitude altimétrica entre o vale fluvial e as áreas montanhosas de onde emergem os sedimentos ( $\geq 300 \mathrm{~m}) ; 2$ ) disposição perpendicular (ou oblíqua) dos sedimentos com relação ao vale principal; 3 ) histórico de chuvas torrenciais; 4) ângulo de declividade médio do leque $\geq 1,5^{\circ}$ (nos demais sistemas fluviais o ângulo de declividade é $\geq 0,4^{\circ}$ ); 5) disponibilidade de sedimentos na bacia a montante; 6) desconfinamento do fluxo; 7) baixa maturidade textural; 8) comprimento limitado a $10 \mathrm{~km}$; 9) atuação de processos erosivos e deposicionais; 10) decrescência granulométrica de montante para jusante; 11) presença de canais de incisão e bajada; 12) perfis longitudinal côncavo e transversal convexo; 13) correlação positiva entre tamanho dos sedimentos e inclinação da vertente; 14) forma radial; 15) presença de fácies diagnósticas dos processos de fluxos de detritos e inundações; 16) processos secundários atuantes na superfície do leque; 17) movimentações tectônicas; 18) inexistência de fácies de planície de inundação. Além dessas características, cabe mencionar que para Oguchi et al., (2001) os leques aluviais tem comprimento superior a $2 \mathrm{~km}$ e inclinação média inferior a $20^{\circ}$.

Alguns pesquisadores utilizaram registros de leques aluviais para reconhecer mudanças ambientais quaternárias. Além disso, puderam verificar movimentos tectônicos sinsedimentares que culminaram na deposição e evolução dos mesmos (Plantz et al., 2019; Finthan e Mamma, 2020; Lopes et al., 2020; Niu et al., 2021; Imei et al., 2021). Importantes também são os trabalhos sobre leques aluviais que verteram sua ótica para os problemas associados ao uso e ocupação desordenada do terreno. Seus autores sugerem atenção do poder público no sentido de evitar problemas (catástrofes) relacionados à erosão interna, deslizamentos de depósitos do tipo fluxo de gravidade, soterramento de áreas urbanas, inundações e poluição de aquíferos (Sobreira, 2001; Lana et al., 2016; Vasconcellos e Kobiyama, 2019).

Em diversas regiões do Brasil, trabalhos de cunho tectônico identificaram depósitos de leques aluviais no preenchimento de grabens cenozoicos (Saadi, 1991; Santos, 1999; Ferreira, 2001; Gontijo, 1999). Em São Paulo, Neves et al., (2005) descreveram leques pré-quaternários no sopé de escarpas de falhas da Serra do Japi. No Espírito Santo, Lana et al., (2016) estudaram leques aluviais quilométricos dominados por fluxo de gravidade.

No Quadrilátero Ferrífero, embora a geomorfologia contenha cristas altas, platôs elevados, cânions profundos e vales amplos, hipoteticamente nesse estudo propícios ao desenvolvimento de leques aluviais, poucos são os trabalhos que estudaram a referida feição sedimentar. Além disso, segundo Varajão(1991), a evolução da paisagem regional foi condicionada por falhamentos distensionais e soerguimentos epirogenéticos que, para Medina et al., (2005), foram mais intensos no Neógeno e Quaternário. Embora a grande amplitude altimétrica e a tectônica ressurgente possam ter contribuídopara o desenvolvimento dos leques regionais, a forte atuação do clima tropical úmido possivelmente viabilizou o consumo dos depósitos, tendoem vista as altas taxas de incisão fluvial, a densidade da vegetação, a instalação de formas erosivas e os adiantados processos pedogenéticos (Lopes et al., 2020).

$\mathrm{Na}$ mesma região citada anteriormente, alguns trabalhos focados em terraços e planícies fluviais descreveram secundariamente leques aluviais descaracterizados por processos erosivos e pedogenéticos nas bacias do rio Piracicaba (Rossi, 2008) e ribeirão Serra Azul (Marques, 1997; Moreira, 1997; Barros, 2015). Estudos mais detalhados sobre o tema são encontrados apenas para as regiões da Chapada da Canga (Castro, 2017) e das bacias dos ribeirões Casa Branca e Piedade (Lopes et al., 2020).

Mediante análises de gabinete e trabalhos de campo, este trabalho buscou reconhecer os depósitos inconsolidados de leques aluviais do Quadrilátero Ferrífero. Tradicionalmente, os 
trabalhos em geomorfologia fluvial da região focaram no entendimento do processo evolutivo da paisagem sob a ótica dos depósitos sedimentares fluviais representados, principalmente, por planícies e terraços de rios (Barros e Magalhães Júnior, 2013; Barros, 2015; Barros e Magalhães Junior, 2018a, b; Barros e Magalhães Júnior, 2020). Nesse sentido, acredita-se que a identificação dos leques aluviais da região possa servir de base para adensamento de trabalhos futuros e contribuir com novas intepretações a respeito da paleogeografia regional.

\section{Localização e caracterização da área de estudo}

O relevo do Quadrilátero Ferrífero é composto por cristas elevadas, escarpas íngremes e vales encaixados. As áreas mais elevadas, com altitudes acima de $1040 \mathrm{~m}$, localizam-se nas megaestruturas proterozoicas (maciço Caraça, sinclinais Gandarela, Dom Bosco, Moeda e Homoclinal do Curral) cujos topos (acima de $1200 \mathrm{~m}$ ) estão sustentados por itabiritos e quartzitos. Já nas áreas mais baixas, entre 720 e $1040 \mathrm{~m}$, estão os complexos granito-gnáissicos e migmatíticos com cursos fluviais encaixados (figura 1).

Dentre as referidas megaestruturas, a crista mais alta está a Leste, no maciço do Caraça, cuja altitude máximaalcança 2072m. Nas proximidades de Ouro Preto, o Pico do Itacolomi também se destaca na paisagem, com $1772 \mathrm{~m}$. Da mesma forma, a Serra da Piedade, uma continuidade da Homoclinal do Curral, configura o marco geográfico mais elevado da região Norte, com $1746 \mathrm{~m}$. As áreas mais rebaixadas encontram-se ao longo dos vales dos rios Paraopeba, Velhas, Piracicaba, Santa Bárbara, Gualaxo do Norte e demais afluentes do rio Doce, com cotas entre 720 e $880 \mathrm{~m}$ (figura 1 ).

Para Lana (2020), o conhecimento sobre a geomorfologia do Quadrilátero Ferrífero remonta ao século XIX, quando Eschewege publicou o primeiro mapa com a distribuição orográfica da região. Em 1933, fazendo alusão à disposição geométrica das serras regionais, Luiz Flores de Morais Rego batiza a região como Quadrilátero Central. No ano de 1953, em referência à geometria e ao erário mineral, Luciano de Morais utiliza pela primeira vez o termo Quadrilátero Ferrífero.

Harder e Chamberlim (1915) observaram que os picos e áreas elevadas eram compostos por quartzitos e itabiritos enquanto xistos, gnaisses e filitos compunham as áreas baixas. Também perceberam que as cotas altimétricas dos topos das serras eram similares. Tais observações os levaram a interpretar uma forte fase erosiva entre o Mesozoico e Paleogeno que teria aplainado as cristas das serras. A perda de massa ocasionou no soerguimento de algumas áreas, fazendo com que os processos erosivos atuassem de maneira diferente nos diversos litotipos. Essa interpretação alimentou os estudos de pesquisadores como De Martone (1940), Freitas (1951) e King (1956).

King (1956) identificou quatro superfícies de aplainamento na região. A primeira e mais alta, denominada Gondwana, teria sido formada no Eocretáceo e estaria entre as cotas altimétricas de 1500 e $1650 \mathrm{~m}$, representada pelo Pico do Itacolomi. A segunda foi gerada no Cretáceo Superior, nomeada por Pós-Gondwana, estaria entre as cotas 1250 e $1400 \mathrm{~m}$ e corresponderia a Serra do Curral. A terceira superfície de aplainamento proposta por King (1956) é a SulAmericana, identificada no vale do Rio Paraopeba, foi gerada no Paleogeno e encontra-se entre as cotas de 850 e $950 \mathrm{~m}$. Por fim a superfície Velhas, representada pelo vale do rio homônimo, remonta ao Neogeno e estaria entre 700 e $750 \mathrm{~m}$.

Dorr (1959) identificou quatro novas superfícies. A primeira na Serra do Caraça em cotas topográficas que variam de 2000 e $2100 \mathrm{~m}$, a segunda na Serra da Piedade entre 1750 e 1850m, a terceira corresponderia a resquícios de superfícies antigas na lateral da Serra do Curral entre 1100 e $1200 \mathrm{~m}$ e, finalmente, a quarta superfície na região de itabirito com colinas entre 1000 e $1100 \mathrm{~m}$.

Os trabalhos de Dorr (1959) foram complementados por autores como Maxwell (1972), Lichte (1979) e Barbosa (1980). O último acreditava ser um equívoco concluir que superfícies em cotas altimétricas diferentes poderiam ter sido geradas por eventos de denudação diferentes. Além da falta de datação dessas superfícies, seria possível que as diferenças na erodibilidade preservassem as áreas de rochas mais resistentes e aplainassem as de rochas mais friáveis, resultando em superfícies com altitudes discrepantes em uma única fase erosiva.

Segundo Varajão (1991), o que define a quantidade de superfícies é a qualidade do material cartográfico utilizado, em termos de escala. Assim, a partir da erodibilidade das rochas, $\mathrm{o}$ autor propôs três superfícies na região: 1) Alta, composta por quartzitos e itabiritos, 2) média, compreendendo os xistos e filitos e, 3) baixa, majoritariamente formada por gnaisses e migmatitos.

Salgado et al. (2006), Salgado et al. (2007) e Salgado et al. (2008) estudaram a denudação 
geoquímica do Quadrilátero Ferrífero e calcularam taxas de erosão por 10Be. Seus resultados demonstraram que a denudação geoquímica é alta em rochas carbonáticas, média em granitos, gnaisses, xistos e filitos e, baixa em quartzitos e itabiritos. As taxas de erosão obtidas foram altas nos granitos e gnaisses, médias nos xistos e filitos e baixas em quartzitos e itabiritos. De acordo com Varajão et al. (2009), as taxas médias de erosão em $7 \mathrm{~m} / \mathrm{Ma}$ são condizentes com os dados da área leste do lineamento transbrasiliano, demonstrando que o relevo regional não é condicionado unicamente pela erosão diferencial, mas também pela neotectônica.
Peifer et al. (2021) também calcularam e cotejaram as taxas de denudação com as diferentes resistências das rochas. Para os mesmos autores, as bacias hidrográficas sustentadas por quartzitos apresentaram as taxas de denudação mais lentas que as compostas por xistos, granitos, ganisses e filitos. Destas últimas, as bacias com granitos, gnaisses e filitos apresentaram as taxas mais elevadas enquanto as bacias com rochas mistas tiveram suas taxas de denudação condicionadas à resistência das litologias preponderantes em cada uma delas.

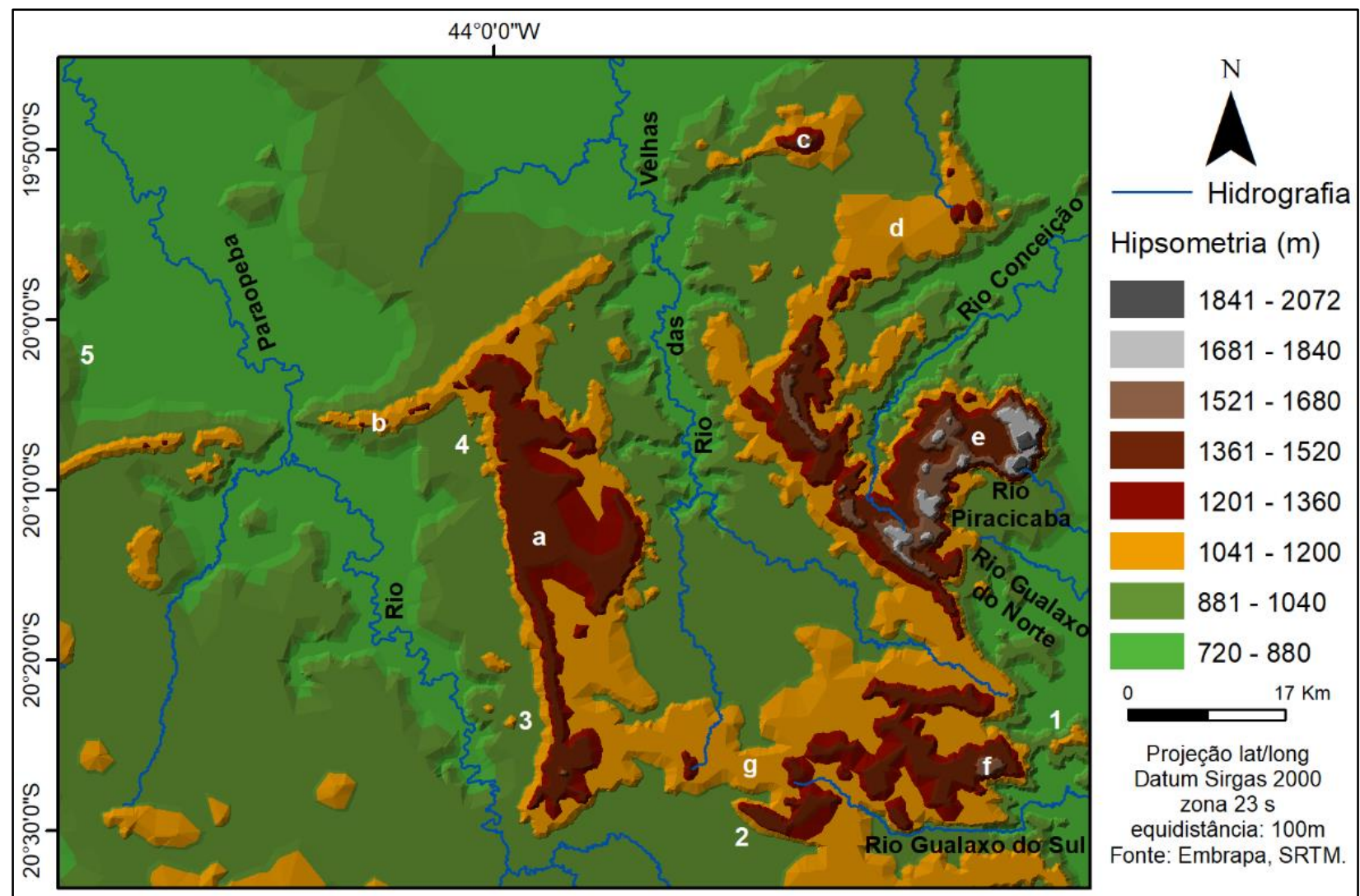

a) Sinclinal Moeda, b) Homoclinal do Curral, c) Serra da Piedade, d) Sinclinal Gandarela, e) Serra do Caraça, f) Pico do Itacolomi, g) Sinclinal Dom Bosco. 1, 2, 3, 4, 5 - Depósitos (leques aluviais) identificados e analisados nesse trabalho

Figura 1. Modelo digital de elevação do Quadrilátero Ferrífero com o posicionamento dos depósitos (leques aluviais) identificados nesse trabalho.

\section{Metodologia}

Reconhecimento dos depósitos em gabinete $\mathrm{O}$ reconhecimento em gabinete refere-se às análises pré-campo que facilitaram e direcionaram os trabalhos práticos. Foram utilizadas duas estratégias de reconhecimento preliminar dos depósitos de leques aluviais. A primeira delas concerne à leitura de trabalhos relacionados ao relevo do Quadrilátero Ferrífero que possam ter descrito, mesmo que de maneira incipiente, rampas de colúvio, tálus e leques aluviais, dos quais destacaram-se Barbosa (1980), Marques (1997), Moreira (1997), Sobreira (2001), Barros (2015), Castro (2017) e Lopes et al. (2020). 
Revista Brasileira de Geografia Física v.14, n.03 (2021) 1296-1311.

A segunda estratégia de reconhecimento preliminar teve enfoque na identificação dos depósitos cenozoicos ao longo das médias e baixas vertentes, por meio da interpretação de mapas geológicos nas escalas 1: 25.000 (Dorr, 1969), 1:50.000 (Baltazar et al., 2005) e 1:100.000 (Ribeiro e Baltazar, 2013). Ainda que estes depósitos estejam descritos nas cartas geológicas como aluvião, eluvião ou coluvião, seu posicionamento somado às informações compiladas dos trabalhos sobre o relevo definiram os locais de maior viabilidade para realização dos trabalhos de campo. Como suporte a esta etapa, utilizando imagens do Google Earth, tentou-se reconhecer patamares topográficos gerados pelo acúmulo de sedimentos em formato semicônico e obter dados topográficos dos seus respectivos vales fluviais, área-fonte e depósitos estudados.

Como os estudos sobre os depósitos quaternários da região estão majoritariamente focados em terraços de rios e os mapas geológicos focados nos aspectos litológicos e estruturais, entende-se que as estratégias de reconhecimento preliminar podem não ser suficientes em algumas porções do Quadrilátero Ferrífero. Nessas mesmas porções, sem menção de depósitos cenozoicos na literatura e tampouco contidos nas bases geológicas, a identificação dos leques aluviais se restringiram a trabalhos de campoao longo do sopé das escarpas.

Reconhecimento dos depósitos em trabalho de campo

Em campo, os depósitos de encosta identificados foram analisados de acordo com critérios espaciais e sedimentológicos para atestar se os mesmos constituem (ou não) fragmentos de antigos leques aluviais, são eles:

-Distribuição espacial dos sedimentos com relação ao vale principal: Os cursos de drenagem das regiões mais baixas e oblíquos aos leques aluviais constituem o limite inferir de colmatação dos referidos depósitos. Sedimentos similares nas duas margens da calha fluvial tendem a configurar, morfologicamente, terraços fluviais pareados (exemplos de terraços com morfologia típica são encontrados em Barros e Magalhães Júnior, 2013; Barros e Magalhães Júnior, 2020).

-Posição altimétrica dos depósitos: Os depósitos de leques aluviais regionais foram descritos por Saadi (1991), Marques (1997), Santos (1999) e Lopes et al. (2020) nos atuais topos de morro e meias vertentes. Em regiões mais baixas e próximas à calha principal os mesmos tendem a ser erodidos pela dinâmica fluvial.

-Decrescência granulométrica para jusante: Em leques aluviais, a brusca perda de energia em função do desconfinamento do fluxo ocasiona na redução granulométrica de montante para jusante (Kesel e Lowe, 1987; Blair e McPherson, 1994). Essa dinâmica condiciona uma estreita relação proporcional entre a declividade dos sedimentos e o tamanho dos clastos. Do contrário, em canais fluviais a continuidade do fluxo confinado não leva a variações granulométricas tão nítidas (Blair e McPherson, 1994).

-Granulometria cascalhosa: Mesmo com a diminuição da profundidade em função do desconfinamentodo fluxo, a declividade doterreno onde há sedimentação de leques aluviais promovem força de tração suficiente para transportar sedimentos arenosos, argilosos e siltosos até os vales fluviais. Assim, os depósitos de leques aluviais serão constituídos por grânulos, seixos, calhause matacões (geralmente angulosos). Fácies de granulometria exclusivamente lamosa tendem a comporo registro sedimentar de planícies de inundação de canais fluviais (Oguchi e Oguchi, 2004; Blair e McPherson, 1994).

-Espessura das fácies diagnósticas de fluxo de detritos e inundação: Depósitos não confinados, como os de leques aluviais, tendem a possuir maior espessura que os confinados, de canais fluviais. Isso porque a continuidade do fluxo dos canais confinados tendem a transportar os sedimentos para jusante enquanto que, em leques aluviais, os sedimentos só são removidos nas altas chuvas torrenciais e consequente novo ciclo de deposição. Assim, na paisagem, as fácies de fluxos de detritos e de inundação tem espessuras maiores se comparadas com as de terraços fluviais.

\section{Resultados}

Depósito 1

O depósito 1 assenta-se na base de um contraforte da serra do Itacolomi, sob os bairros Cabanas, Santa Rita de Cássia e Nazaré, no município de Mariana (figuras 1 e 2a). Sua identificação consistiu, primeiramente, na leitura de sua descrição morfométrica e sedimentar encontrada em Sobreira (2001). De acordo com o autor, toda essa região possui uma área de $1,3 \mathrm{~km}^{2}$, compreendendo um grande depósito de tálus com formato de leque que pode alcançar os $10 \mathrm{~m}$ de espessura. Apesar de suas dimensões expressivas, 
o depósito em questão não foi representado no mapa geológico.

Seus sedimentos são truncados pela planície do córrego do Seminário e rio do Carmo, sendo os mesmos identificados apenas em sua margem direita, com relação a jusante. Nessa região os sedimentos encontram-se em aproximadamente $804 \mathrm{~m}$ de altitude, enquanto que para montante sua altitude alcança os $909 \mathrm{~m}$. Caracterizam-se pela presença de seixos, grânulos, calhaus e matacões sustentados por matriz arenolamosa (figuras $2 b, c$ e d). Além disso, verificou-se que os referidos clastos sustentados pela matriz ficam menores no sentido jusante (figuras $2 \mathrm{ce} d$ ).

Litologicamente, o depósito 1 está assentado sobre os xistos, filitos e quartzitos do Grupo Sabará. A altura máxima da área-fonte dos sedimentos está a cerca de $330 \mathrm{~m}$ acima do vale fluvial e possui aproximadamente uma área de 0,9 $\mathrm{km}^{2}$, com xistos e filitos do Grupo Nova Lima aflorando em sua maior parte. De maneira subordinada tem-se os quartzitos do Grupo Itacolomi e xistos e filitos da Formação Barreiro (Dorr, 1969; Baltazar et al., 2005).

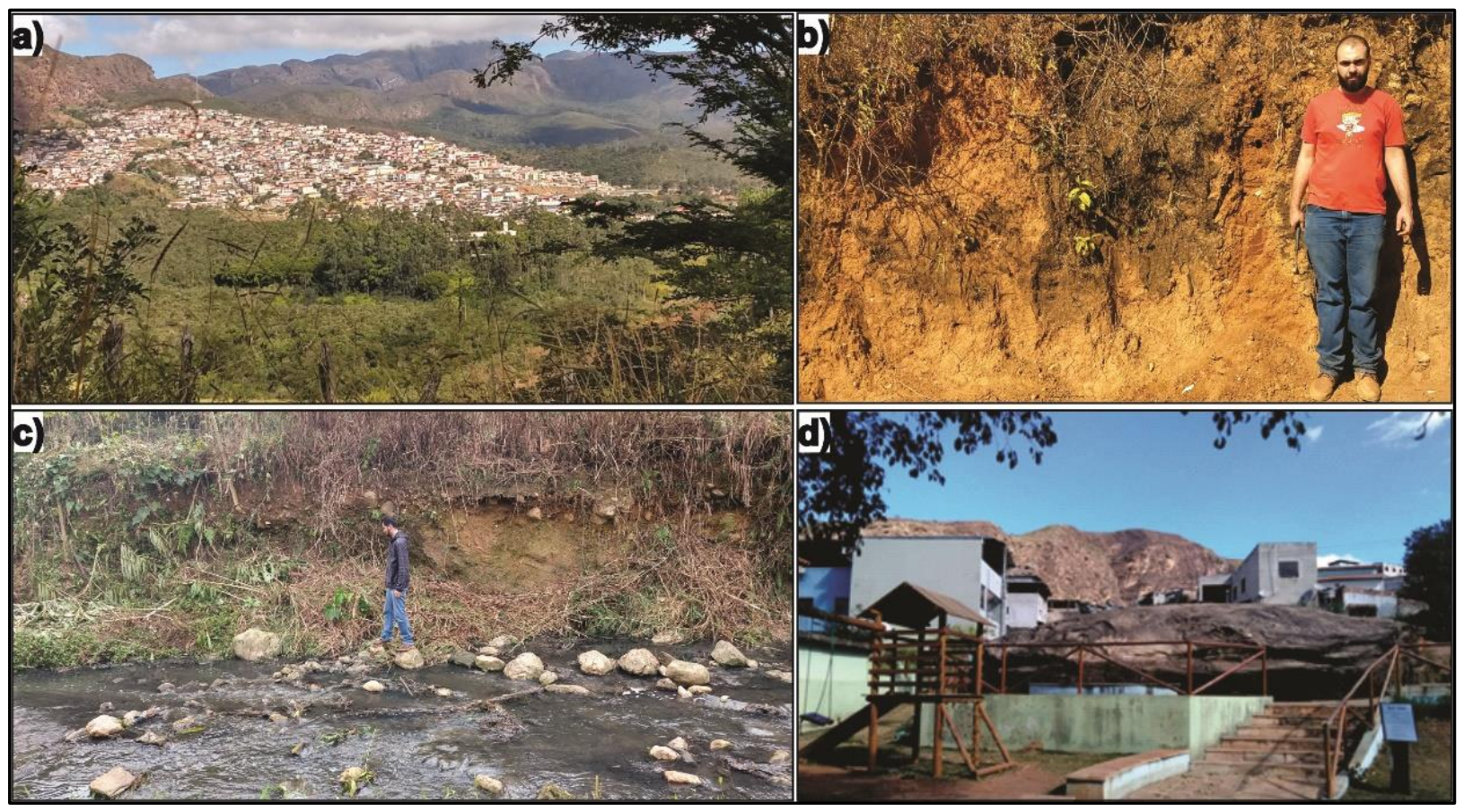

Figura 2. a) Visada para Sudoeste da região onde foi identificado o depósito 1 e sua respectiva área -fonte. b) Matriz a reno-la mosa que sustenta os seixos, grânulos, calhaus e matacões. c) Parede do córrego Seminário onde os cascalhos tem dimensões limitadas a 1,5m. d) Bloco de elevada dimensão encontrado nas proximidades da área -fonte.

\section{Depósito 2}

O depósito 2 foi identificado no sopé da Serra de Ouro Branco (figura 1). A base de toda referida serra está preenchida por um grande complexo de depósitos aluvio-coluvionares que, juntos, somam cerca de $15 \mathrm{~km}^{2}$. Sua investigação em gabinete se deu através da leitura do trabalho de Barbosa (1980) onde o autor pressupõe que sua deposição foi ocasionada pela reativação tectônica da serra de Ouro Branco. No mapa geológico foi classificado como tálus e coluvião.

Como se trata de uma área extensa, optouse pelo estudo da região com maior potencial de preservação dos sedimentos já que os mesmos se encontram alterados por atividades antrópicas (figura 3a). Os sedimentos do depósito em questão se estendem desde o sopé da Serra de Ouro Branco, em altitudes que podem alcançar $1017 \mathrm{~m}$, até os arredores da rodovia MG 443 a $958 \mathrm{~m}$ de altitude (figura 3a).

Em trabalhos de campo foi possível verificar sedimentos maciços e cascalhosos sustentados por matriz arenosa associados a sedimentos puramente maciços e cascalhosos (figura 3b). Juntos esses sedimentos alcançam até $2,3 \mathrm{~m}$ de espessura e, seguem um padrão de diminuição e arredondamento dos clastos para jusante.

Esses sedimentosestão assentados sobre os xistos e filitos indivisos do Grupo Nova Lima. Sua área-fonte, com cerca de $0,24 \mathrm{~km}^{2}$ (figura $3 \mathrm{c}$ ), possui amplitude altimétrica de aproximadamente 
$500 \mathrm{~m}$ sendo totalmente composta por quartzitos e filitos indivisos do Grupo Itacolomi (Dorr, 1969; Baltazar et al., 2005).

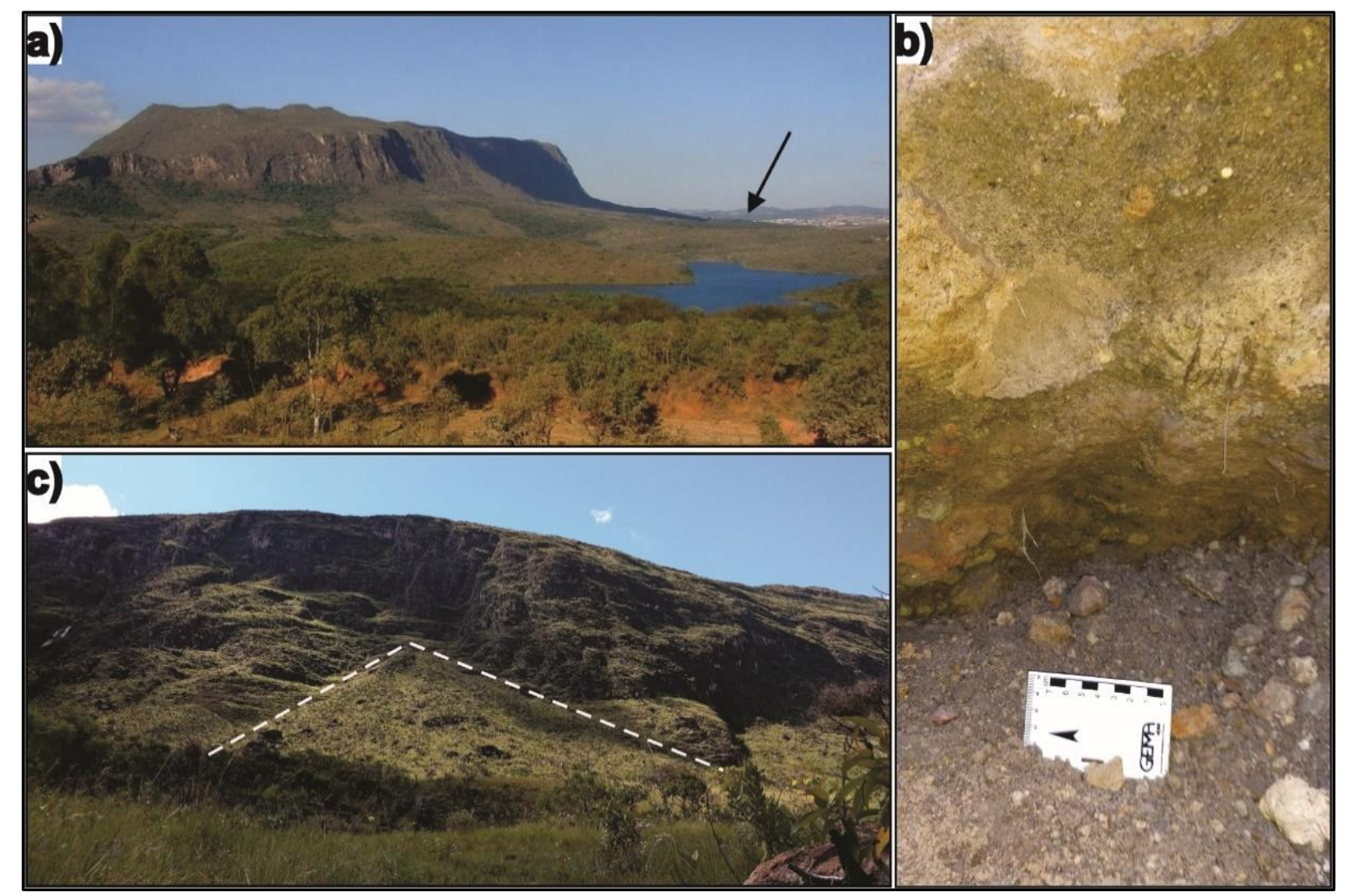

Figura 3. a) Visada para Leste da Serra de Ouro Branco com o complexo de depósitos alúvio -coluvionar em sua base (foto de Glauco Umbelino, 2007). b) sedimentos maciços e cascalhosos sustenta dos por matriz arenosa associados a sedimentos puramente ma ciços e cascalhosos. c) Parte da área -fonte do depósito onde é possível verificar um prová vel desconfinamento do fluxo.

\section{Depósito 3}

O depósito 3 encontra-se na zona rural da cidade Belo Vale, na base da serra da Moeda, sobre a colinas graníticas, gnáissicas e migmatíticas do Complexo Bonfim (figura 1). Trata-se de uma acumulação sedimentar bastante dissecada pelo ribeirão Boa Esperança e demais cursos fluviais de ordem hierárquica inferior, todos afluentes da margem direita do Rio Paraopeba, com relação a jusante (figura 1).

Embora não mencionado na literatura geomorfológica, foi possível o identificar, em gabinete, através da interpretação dos mapas geológicos onde os mesmos estão legendados como depósitos alúvio coluvionares. Conforme a figura $4 b$, em trabalhos de campo verificou-se que o depósito tem constituição modal cascalhosa, podendo alcançar $1 \mathrm{~m}$ de espessura, em cotas altimétricas que variam de 907 a 1290m.

Sua área-fonte, na Serra da Moeda, foi estimada em cerca de $1 \mathrm{~km}^{2}$, estando seu ponto mais alto $500 \mathrm{~m}$ acima do atual vale do rio Boa Esperança. Essa área possui boa variedade de litotipos, além das lateritas e detritos ferruginosos, afloram quartzitos da Formação Moeda, filitos da Formação Batatal, quartzitos do Grupo Itacolomi e, em sua maior parte, itabiritos da Formação Cauê (Dorr, 1969; Baltazar et al., 2005). 


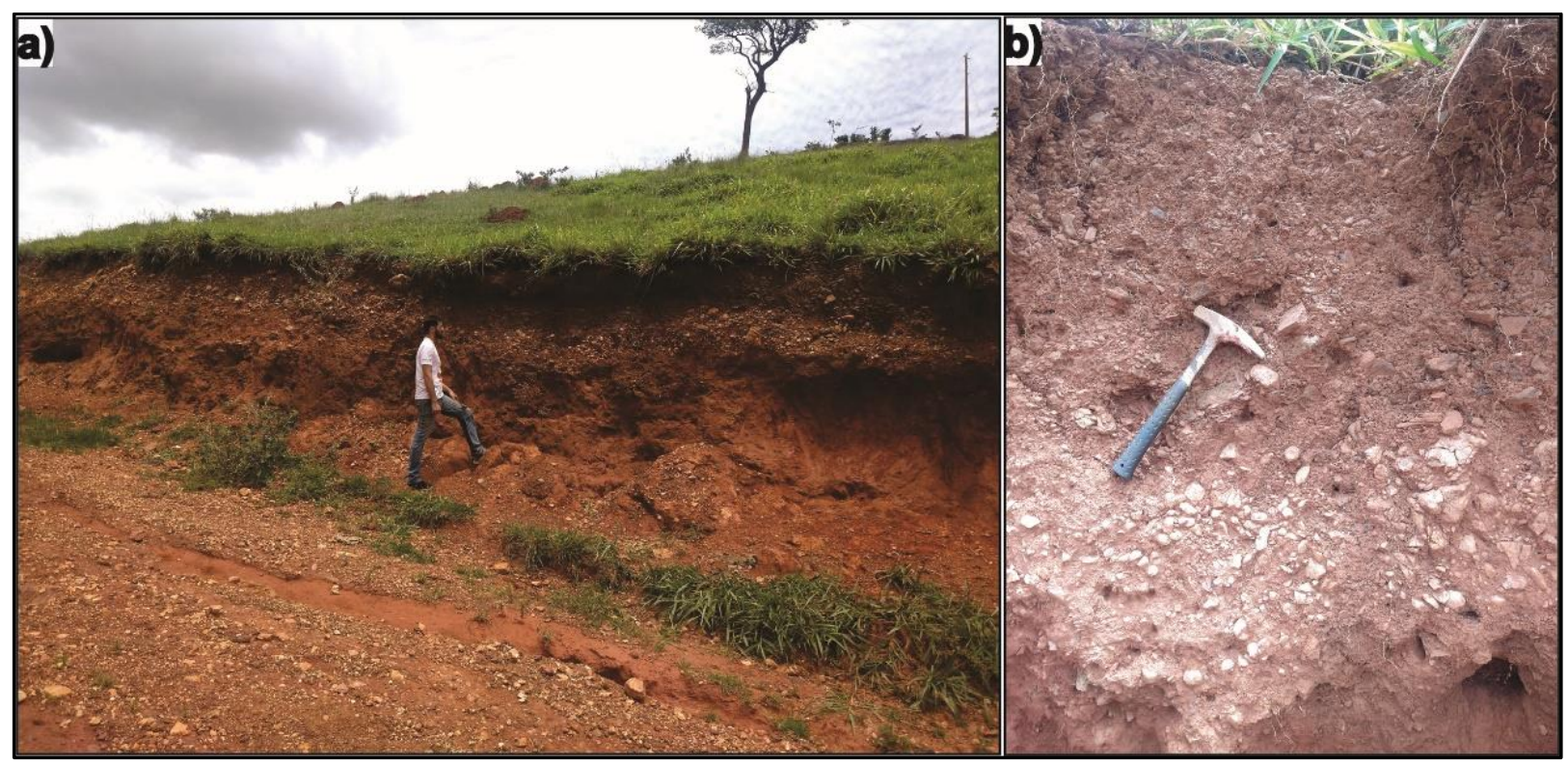

Figura 4. a) Foto parcial do depósito 3, assentado sobre as colinas do Complexo Bonfim. b) Foto em detalhe dos sedimentos cascalhosos.

\section{Depósito 4}

O depósito 4 está assentado na base da Serra da Moeda, margem direita do Rio Paraopeba. Truncado pelo ribeirão Piedade, seus fragmentos proximais foram identificados na região do distrito de Piedade de Paraopeba enquanto os mais distais nas proximidades do distrito de Aranha. Não consta nos mapas geológicos, sendo seu estudo preliminar ocorrido através da leitura dos trabalhos de Lopes et al. (2019) e Lopes et al. (2020).

Os autores anteriormente mencionados acreditam que se trata de um depósito de leque aluvial completamente fragmentado pelos cursos de drenagem. Para Lopes et al. (2020), os fragmentos encontrados só estão preservados graças ao possível posicionamento adjacente às zonas de falhas e fraturas.

Em trabalhos de campo foram identificados sedimentos majoritariamente maciços de cascalhos sustentados por material lamoso, que podem ultrapassar $2,5 \mathrm{~m}$ de espessura (figura 5a, b). De maneira menos frequente foram identificados sedimentos cascalhosas com estratificações cruzadas acanaladas, remetendo a fluxos canalizados (figuras 5b, c). Os referidos sedimentos estão assentados sobre as colinas graníticas, gnáissicas e migmatíticas do Complexo Bonfim, suas cotas altimétricas variam de $844 \mathrm{~m}$ nas porções mais distais a $912 \mathrm{~m}$ nas proximais.

A área da fonte dos sedimentos, na Serra da Moeda, possui cerca de $10 \mathrm{~km}^{2}$, estando seu ponto mais alto $532 \mathrm{~m}$ acima do atual vale do ribeirão Piedade. É a área-fonte com maior diversidade de litotipos entre os cinco depósitos estudados, tem-se rochas metaultrabásicas do Grupo Quebra Osso, quartzitos da Formação Moeda, xistos e filitos do Grupo Nova Lima, filitos da Formação Batatal e os Itabiritos da Formação Cauê (Dorr, 1969; Baltazar et al., 2005). 


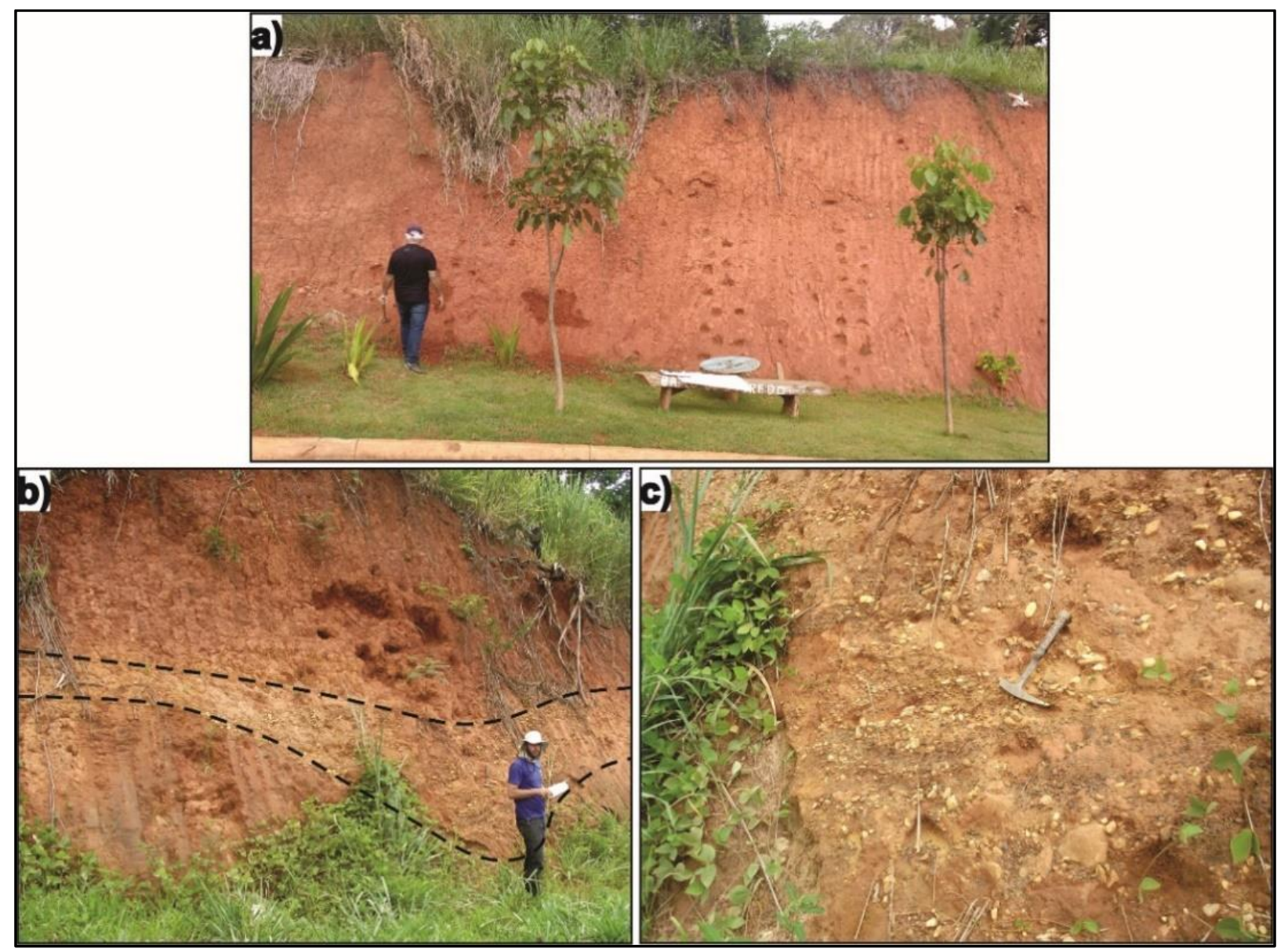

Figura 5. a) Acumulação maciça composta por ca scalhos de ta manhos diversos sustentados por ma triz la mosa (foto de Lopes et al., 2020). b) Sedimentos de fluxo canalizado sotopostos aos sedimentos da figura 5a. c) Detalhe dos sedimentos de fluxo canalizado, com estratos cruzados.

\section{Depósito 5}

O depósito 5 encontra-se na base da Serra da Saudade, é cortado pela estrada que liga Serra Azul a Mateus Leme. Seus sedimentos são dissecados pelo córrego Bom Gardim, afluente da margem esquerda do ribeirão Serra Azul. As áreas mais baixas e próximas ao ribeirão Serra Azul encontram-se a $788 \mathrm{~m}$ de altitude enquanto as mais altas, próximas a Serra da Saudade, em 1002m de altitude.

Os estudos de gabinete basearam-se na leitura dos trabalhos de Marques (1997), Moreira (1997) e Barros (2015). Os autores sugerem que sua deposição ocorreu em função do soerguimento da serra da Saudade. Esse depósito não consta no mapa geológico disponível para região, provavelmente em função da pequena escala, em 1:100.000. Assim como nos demais estudados, há boa presençade sedimentos maciçose cascalhosos, por vezes, sustentados por matriz areno-lamosa assentados sobre o embasamento granito-gnáissico migmatítico do Complexo Belo Horizonte (figuras $6 a$, b). Em alguns locais, tal acumulação sedimentar pode alcançar os 3,5m (figura 6c).

Sua área-fonte, a Serra da Saudade, possui cerca de $0,93 \mathrm{~km}^{2}$ e tem como substrato rochoso as unidades metamáficas do Supergrupo Rio das Velhas, como clorita xistos e sericita-clorita xistos (Ribeiro e Baltazar, 2013). A amplitude altimétrica entre a Serra Azul e o ribeirão homônimoé de cerca de $325 \mathrm{~m}$. 


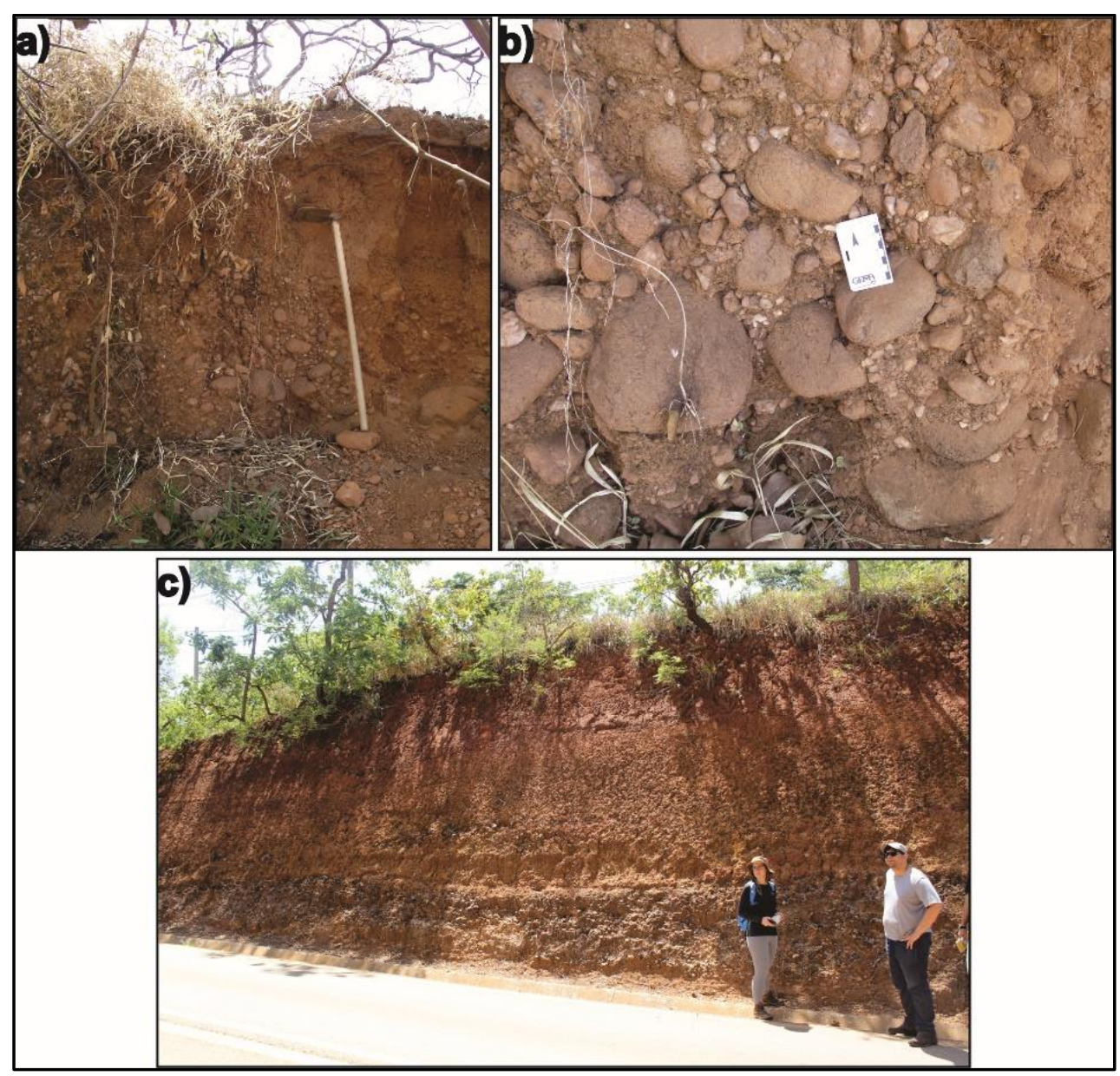

Figura 6. a) Sedimentos maciços e cascalhosos do depósito 5. b) Sedimentos cascalhosos de tamanhos diversos, em detalhe.c) Perfil na margem da estrada que liga Mateus Leme a Serra Azul (Foto de Renata Jordan, 2019).

\section{Discussões}

A tabela 1 contém as cartas geológicas e os referenciais teóricos que contribuíram para identificação em gabinete dos depósitos estudados. As folhas geológicas mencionadas correspondem às mapeadas por Baltazar et al. (2005), em escala 1: 50.000. Na mesma tabela estão os dados altimétricos das porções mais a montante e a jusante dos depósitos bem como a amplitude altimétrica entre sua área-fonte e seu respectivo vale fluvial. Vale ressaltar que a estratégia adotada contribuiu satisfatoriamente para o direcionamento dos trabalhos de campo e, consequentemente, para identificação dos depósitos estudados.

As dezoito características intrínsecas a leques aluviais definidas por Blair e McPherson (1994) estão descritas e enumeradas na seção introdutória do presente estudo. Dez delas são concernentes aos aspectos sedimentares $(2,5,7,9$, $10,11,13,15,16$ e 18), cinco aos morfométricos e morfológicos $(4,6,8,12$ e 14) e outras três relacionam-se aos aspectos geomorfológicos da região (1, 3 e 17). Em gabinete foi possível verificar que a amplitude altimétrica dasáreas onde foram identificados os depósitos condiz com os valores estabelecidos por Blair e McPherson (1994) para regiões propícias ao desenvolvimento de leques aluviais, superiores a $300 \mathrm{~m}$ (tabela 1). Tal conformação geomorfológica é consenso na literatura, diversos são os autores que descreveram leques aluviais em regiões com encostas abruptas, alta amplitude altimétrica, vales encaixados e planícies abertas (Cable et al., 2018; Vasconcellos e Kobiyama, 2019; Carniel, 2019; Nogueira et al., 2020; Camacho et al., 2020; Welivitiya et al., 2020; Vasconcellos et al., 2021; dentre outros).

Além da alta amplitude altimétrica, o posicionamento dos sedimentos em cotas topográficas elevadas é uma característica descrita regionalmente para depósitos de leques aluviais, conforme os trabalhos de Saadi (1991), Marques (1997), Santos (1999), Barros (2015), e Lopes et al. (2020). 
Tabela 1 - Cartas geológicas, referenciais teóricos, posição altimétrica dos depósitos e amplitude altimétrica entre a área-fonte dos depósitos e seu respectivo vale fluvial.

\section{Reconhecimento dos leques aluviais em gabinete}

\begin{tabular}{|c|c|c|c|c|}
\hline Depósitos & Mapa geológico & $\begin{array}{l}\text { Referencias } \\
\text { teóricos }\end{array}$ & $\begin{array}{c}\text { Posição } \\
\text { altimétrica dos } \\
\text { sedimentos }\end{array}$ & $\begin{array}{c}\text { Amplitude } \\
\text { altimétrica da } \\
\text { área }\end{array}$ \\
\hline 1 & - & Sobreira (2001) & 804 a $909 m$ & $330 \mathrm{~m}$ \\
\hline 2 & $\begin{array}{c}\text { Folha Ouro Branco } \\
\text { (SF-23-X-A-III-4) }\end{array}$ & Barbosa (1980) & 958 a $1017 \mathrm{~m}$ & $500 \mathrm{~m}$ \\
\hline 3 & $\begin{array}{c}\text { Folha Casa da Pedra } \\
\text { (SF-23-X-A-III-3) }\end{array}$ & - & 907 a $1290 m$ & $500 \mathrm{~m}$ \\
\hline 4 & - & $\begin{array}{c}\text { Lopes et al. (2019) } \\
\text { e Lopes et al. } \\
(2020) .\end{array}$ & 844 a $912 m$ & $532 \mathrm{~m}$ \\
\hline 5 & - & $\begin{array}{c}\text { Marques (1997), } \\
\text { Moreira (1997) e } \\
\text { Barros (2015). }\end{array}$ & 788 a $1002 \mathrm{~m}$ & $325 \mathrm{~m}$ \\
\hline
\end{tabular}

Em trabalhos de campo foi possível identificar demais características concernentes a leques aluviais elencadas por Blair e McPherson (1994), conforme a tabela 2. A primeira delas, comumente visualizada em todos os depósitos, é o fato de que estão dispostos de maneira oblíqua aos seus respectivos vales fluviais. Outras duas características comuns são a inexistência de depósitos de planície de inundação e a acentuada espessura de depósitos cascalhosos, com destaque para o depósito 1 que pode alcançar os $10 \mathrm{~m}$ (tabela 2).

A decrescência granulométrica no sentido jusante foi perceptível nos depósitos 1 e 2, demonstrando forte queda energética $e$ consequente deposição dos sedimentos mais densos a montante e mais finos a jusante. A correlação positiva entre as áreas declivosas e o tamanho dos sedimentos foi notado apenas no depósito 1 , onde os maiores matacões estão nas regiões mais declivosas e próximas a área-fonte, $o$ que não é verificado nas porções a jusante e próximas às planícies do córrego do Seminário e rio do Carmo, onde os calhaus possuem comprimento limitado a $1,5 \mathrm{~m}$. Para Blair e McPherson (1984) a deposição de clastos maiores e próximos à área-fonte é uma característica intrínseca a leques aluviais quando há desconfinamento do fluxo e queda da capacidade e competência do mesmo.

Segundo a classificação das litofácies fluviais de Miall (1978), sedimentos de composição cascalho maciço clasto suportado e cascalho matriz suportado correspondem, respectivamente, a sedimentos transportados por fluxos detritos pseudoplásticos e plásticos. Conforme a descrição dos depósitos e a tabela 2 , tais sedimentos foram amplamente identificados nas acumulações estudadas. Para Blair e McPherson (1994), fácies de fluxos de detritos são diagnósticas de leques aluviais. De acordo com Kesel e Lowe (1987), leques aluviais gerados em climas áridos são $85 \%$ compostos por fácies colmatadas por fluxos de detritos. Plantz et al. (2019) tambéminterpretaram a mesma tipologia de depósito como fragmentos de leques aluviais.

Com base na descrição e comparação com a literatura é possível afirmar que os depósitos estudados foram depositados em contextos de leques aluviais, com alta amplitude energética cujos picos inferiores levaram a sedimentação de fragmentos de dimensão e composição diversas. Essa sedimentação se deu nas altas, médias e baixas vertentes, de maneira oblíqua aos seus respectivos paleo-vales. O desconfinamento do fluxo verificado no depósito 2 corrobora a 
interpretação de ambiente deposicional por leques aluviais. Acredita-se que esse desconfinamento não foi tão perceptível nos depósitos 1, 2, 4 e 5 em função de seu desmantelamento ocasionado por processos antrópicos e naturais, conforme descrito por Lopes et al. (2020). Estudos geomorfométricos futuros podem fornecer respostas mais sólidas a esse respeito, já que tal abordagem relaciona variáveis próximas à morfologia e abarca os aspectos denudacionais e agradacionais em contexto amplo (Silveira e Silveira, 2020)

No desmantelamento anteriormente mencionado, os acelerados processos intempéricos e erosivos do clima tropical úmido somaram-se ao uso e ocupação das áreas onde estão colmatados os leques aluviais do Quadrilátero Ferrífero. Esses mesmos fatores levaram Anstey (1965) a adjetivar os leques de regiões úmidas como "depósitos de vida curta". Dessa forma, conforme Saito e Oguchi (2005), tornam-se desconhecidos e, quando inseridos na geomorfogênese de suas respectivas regiões, são descritos como meras pilhasestéreis de cascalhos erodidos e vegetados. Este estudo demonstra que apesar de descaracterizados pelos processos erosivos, as acumulações ainda preservadas tem potencial para fornecer importantes informações sobre o contexto paleoambiental recente do Quadrilátero Ferrífero.

Tabela 2 - Posição com relação ao vale principal, espessura máxima e características sedimentares observadas em trabalhos de campo.

Reconhecimento dos leques aluviais em trabalhos de campo

\begin{tabular}{|c|c|c|c|c|c|}
\hline Depósito & Posição & $\begin{array}{l}\text { Espessura } \\
\text { máxima }\end{array}$ & $\begin{array}{l}\text { Composição } \\
\text { granulométrica }\end{array}$ & $\begin{array}{l}\text { Decrescência } \\
\text { granulométrica }\end{array}$ & $\begin{array}{l}\text { Declividade } \mathrm{x} \\
\text { tamanho dos } \\
\text { grãos }\end{array}$ \\
\hline 1 & $\begin{array}{l}\text { Oblíquo ao rio do } \\
\text { Carmo }\end{array}$ & $10 \mathrm{~m}$ & $\begin{array}{c}\text { Cascalho } \\
\text { sustentado por } \\
\text { matriz lamosa }\end{array}$ & $\begin{array}{l}\text { Montante para } \\
\text { jusante }\end{array}$ & $\begin{array}{c}\text { Cascalhos } \\
\text { maiores em áreas } \\
\text { mais declivosas. }\end{array}$ \\
\hline 2 & $\begin{array}{l}\text { Base da Serra de } \\
\text { Ouro Branco }\end{array}$ & $2,3 \mathrm{~m}$ & $\begin{array}{c}\text { Cascalho e } \\
\text { cascalho } \\
\text { sustentado por } \\
\text { matriz arenosa }\end{array}$ & $\begin{array}{l}\text { Montante para } \\
\text { jusante }\end{array}$ & - \\
\hline 3 & $\begin{array}{l}\text { Oblíquo ao rio } \\
\text { Paraopeba }\end{array}$ & $3 \mathrm{~m}$ & Cascalho & - & - \\
\hline 4 & $\begin{array}{l}\text { Oblíquo ao rio } \\
\text { Paraopeba }\end{array}$ & $2,5 \mathrm{~m}$ & $\begin{array}{c}\text { Cascalho } \\
\text { sustentado por } \\
\text { matriz lamosa }\end{array}$ & - & - \\
\hline 5 & $\begin{array}{l}\text { Oblíquo ao ribeirão } \\
\text { Serra Azul }\end{array}$ & $3,5 \mathrm{~m}$ & $\begin{array}{c}\text { Cascalho e } \\
\text { cascalho } \\
\text { sustentado por } \\
\text { matriz lamosa }\end{array}$ & - & - \\
\hline
\end{tabular}

\section{Considerações finais}

Através da análise dos resultados obtidos em gabinete e trabalhos de campo é possível fazer as seguintes considerações:

1) Tanto a interpretaçãodos mapas geológicos quanto a leitura de textos relacionados à geomorfologia do Quadrilátero Ferrífero foram eficientes no direcionamento dos trabalhos de campo e identificação dos depósitos de leques aluviais.

2) Em trabalhos de campo foi possível evidenciar que os 5 depósitos estudados estão oblíquos com relação ao vale principal e são constituídos por espessos pacotes depositados por fluxos de detritos, sendo que os depósitos 1 e 2 possuem diminuição granulométrica de montante para jusante. Tais características evidenciam 
fortemente que se tratam de paleo-sistemas deposicionais de leques aluviais.

3) A escassez de trabalhos relacionados a leques aluviais em uma região extremamente propícia ao desenvolvimento das referidas feições potencializa a importância do presente estudo e ressalta a necessidade de estudos mais completos e integrados ao processo evolutivo da paisagem.

\section{Agradecimentos}

Fabrício Antonio Lopes agradece ao Conselho Nacional de Desenvolvimento Científico e Tecnológico (CNPq) pela concessão da bolsa de doutorado e taxa de bancada no período de realização desse estudo.

Renato Coelho Dias agradece à Coordenação de Aperfeiçoamento de Pessoal de Nível Superior (CAPES) pela concessão da bolsa de mestrado no período de realização desse estudo.

\section{Referências}

Baltazar, O.F., Baars, F.J., Lobato, L.M., Reis, L.B., Achtschin, A.B., Berni, G.V., Silveira, V.D. 2005. Mapa Geológico Brumadinho na Escala 1:50.000 com Nota Explicativa. In: Projeto Geologia do Quadrilátero Ferrífero Integração e Correção Cartográficaem SIG com nota explicativa. Lobato et al. (2005) CODEMIG. Belo Horizonte.

Babič, M., Petrovič, D., Sodnik, Jošt., Soldo, Božo., Komac, Marko., Chernieva, O., Kovačič, M., Mikoš, M., Calì, M. 2021. Modeling and Classification of Alluvial Fans with DEMs and Machine Learning Methods: A Case Study of Slovenian Torrential Fans. Remote Sens [online] 13.1 Disponível: https://doi.org/10.3390/rs13091711. Acesso maio 2021.

Barbosa, G.V. 1980. Superfícies de erosão no Quadrilátero Ferrífero. Revista Brasileira de Geociências [online] 10. Disponível: http://www.ppegeo.igc.usp.br/index.php/rbg/ar ticle/view/12331. Acesso 15 dez. 2020.

Barros, L.F.P., Magalhães Junior, A. P. 2020. Late quaternary landscape evolution in the Atlantic Plateau (Brazilian highlands): Tectonic and climatic implications of fluvial archives. Earth Science Reviews [online] 207. Disponível: https://doi.org/10.1016/j.earscirev.2020.10322 8. Acesso 12 de dez. 2020.

Barros, L.F.P., Magalhães Junior, A. P. 2018a. Reconstituição de eventos geomorfológicos no Quadrilátero Ferrífero/MG a partir de registros deposicionais fluviais: a bacia do rio Paraopeba.
Quaternary and Environmental Geoscience [online] $9 . \quad$ Disponível: https://revistas.ufpr.br/abequa/article/view/512 35. Acesso 31 nov. 2020.

Barros, L.F.P., Magalhães Junior, A.P. $2018 b$. Morfogênese no Quadrilátero Ferrífero/MG no Quaternário Superior: processos fluviais e condicionantes paleoambientais na bacia do rio das velhas. Revista brasileira de Geomorfologia [online] $19 . \quad$ Disponível: http://dx.doi.org/10.20502/rbg.v19i3.1305. Ace sso jan. 2020.

Barros, L.F.P. 2015. Implicações Geomorfológicas e Paleoambientais de Registros Sedimentares Fluviais do Quadrilátero Ferrífero - Minas Gerais. Tese de doutorado em Geografia, Instituto de Geociências, Universidade Federal de Minas Gerais, 127 p.

Barros, L.F.P., Magalhães Junior A. P. 2013. Quaternary alluvial sedimentation in the Conceição river valley, southeastem Brazil. Brazilian Journal of Geology [online]. Diponível:10.5327/Z231748892013000300009 . Acesso 04 abr. 2019.

Blair T.C., McPherson J.G. 1994. Alluvial fans and their natural distinction from rivers based on morphology, hydraulic processes, sedimentary processes, and facies assemblages. Journal of Sedimentary Research [online] 64. Disponível: http://dx.doi.org/10.1306/D42681B2-2B26 11D7-8648000102C1865D. Acesso $20 \mathrm{fev}$. 2019.

Bull W.B. Alluvial fans. 1968. Jour. of Geol. Educ. [online] 16.

Disponível: https://www.tandfonline.com/doi/abs/10.5408/ 0022-1368-XVI.3.101. Acesso: set. 2019.

Cable, S., Christiansen, H.H., WestergaardNielsen, A., Elberling, B. 2018. Geomorphological and cryostratigraphical analyses of the Zackenberg Valley, NE Greenland and significance of Holocene alluvial fans. Geomorphology [online] 303. Disponível: https://doi.org/10.1016/j.geomorph.2017.11.00 3. Acesso maio de 2021.

Castro, P.T.A. 2017. Geologia da Chapada de Canga. In: Carmo F.F., Kamino L.H.Y. (Orgs). Chapada de Canga: patrimônionatural e cultural de relevante interesse para a conservação. Instituto Pristino, 3i editora, 360p.

Camacho, M.E., Quesada-Román, A., Mata, R., Alvarado A. 2020. Soil-geomorphology relationships of alluvial fans in Costa Rica. Geoderma Regional [online] 21. Disponível: 
Revista Brasileira de Geografia Física v.14, n.03 (2021) 1296-1311.

https://doi.org/10.1016/j.geodrs.2020.e00258. Acesso em maio de 2021.

De Martone, E. 1940. Problèmes Morphologiques du Brésil Tropical Atlantique. Annales de Géographie. I (XIV-XVI): 1-27; 126-129.

Dorr, J.V.N. 1969. Physiographic, stratigraphic and structural development of the Quadrilátero Ferrífero, Minas Gerais, Brazil. USGS/DNPM. Professional Paper 641(A).

Ferreira, M. F. M. 2001. Geomorfologia e análise morfotectônica do alto vale do Sapucaí- Pouso Alegre (MG). Universidade Estadual Paulista, São Paulo, Tese de Doutoramento em Geociências 276p.

Finthan, B., Mamman, Y.D. 2020. The lithofacies and depositional paleoenvironment of the Bima Sandstone in Girei and Environs, Yola Arm, Upper Benue Trough, Northeastern Nigeria. Journal of Africa Earth Sciences [oline] 169. Disponível:https://doi.org/10.1016/j.jafrearsci. 2020.103863. Acesso maio 2021.

Freitas, R.O. 1951. Relevos policíclicos na tectônica do Escudo Brasileiro. Boletim Paulista de Geografia [online] 7. Disponível: https://www.agb.org.br/publicacoes/index.php/ boletim-paulista/article/view/1381. Acesso out. 2020.

Gontijo, A.H.F. 1999. Morfotectônica do médio vale Rio Paraíba do Sul: região da Serra da Bocaina, estados de São Paulo e Rio de Janeiro. UniversidadeEstadual Paulista, SãoPaulo, Tese de Doutoramento em Geociências 259p.

Harder, E.C., Chamberlin, R.T. 1915. The geology of Central Minas Gerais. Journal of Geology [online] 23.2 Disponível: https://www.journals.uchicago.edu/doi/10.1086 /622244. Acesso jun. 2019.

Harvey, A., Stokes, M., Mather, A., Whitfield, E. 2018. Spatial characteristics of the Pliocene to modern alluvial fan successions in the uplifted sedimentary basins of Almería, SE Spain: review and regional synthesis. Geological Society [online] 440. Disponível: https://doi.org/10.1144/SP440.5. Acesso maio 2021.

Imei, S., Sadough, H., Bahrami, S., Mehrabian, A., Nosrati, K. Geomorphological controls on vegetation changes: a case study of alluvial fans in southwest of Miami City, Northeastern Iran. Arabian Journal of Geosciences [online] 14. Disponível:https://link.springer.com/article/10. 1007/s12517-021-06704-4. Acesso maio 2021.

Kesel, R.H., Lowe, D. R. 1987. Geomorphology and Sedimentology of the Toro Amarillo
Alluvial Fan in a Humid Tropical Environment, Costa Rica. Geografiska Annaler [online] 69. Disponível: https://doi.org/10.2307/521369 8599. Acesso abr. 2010.

King, L. 1956. A geomorfologia do Brasil oriental. Revista Brasileira de Geografia 18, 147-265.

Lana, C. E. 2020. A geomorfologia do Quadrilátero Ferrífero. In: Castro P.T.A., Endro I., Gandini A.L (orgs). 2020. Quadrilátero Ferrífero: Avanços do conhecimento nos últimos 50 anos. Belo Horizonte, 3 i editora, 480p.

Lana, C.E., Castro, P.T.A. 2010. Variabilidade morfológica em níveis de base do rio Maracujá (Quadrilátero Ferrífero MG): influências litológicas, estruturais e de reativações cenozoicas. Revista Brasileira de Geomorfologia [online]11. Disponível: http://dx.doi.org/10.20502/rbg.v11i1.138. Acesso jan. 2019.

Lichte, M. 1979. Morphologie Untersuchung in der Serra do Caraça und ihrem Vorland. Universität zu Göttigen, Göttigen. Diss. Master. 139p.

Lopes, F.A., Lana, C.E., Castro, P.T.A., Lana, C.C. 2020. Paleomorphology of the northwestern of the Quadrilátero Ferrífero (Central Brazil): Stratigraphic and geochronological evidence of a pleistocene alluvial fan system. Quaternary International [online] 542. Disponível: https://doi.org/10.1016/j.quaint.2020.02.025. Acesso set. 2020.

Lopes, F.A., Lana, C.E., Castro, P.T.A. 2019. Sedimentologia e Geocronologia Aplicadas a Investigação da Influência da Mineração de Ferro no Assoreamento de Afluentes do Rio Paraopeba, Oeste do Quadrilátero Ferrífero, MG, Brasil. Anuário doInstituto de Geociências [online] 42.4 Disponível: https://doi.org/10.1016/j.quaint.2020.02.025. Acesso jan. 2020.

Maxwell, C.H. 1972. Geology and ore deposits of the Alegria District, Minas Gerais, Brazil. US Geological Survey Prof. Paper 341, 72p.

Marques, M.R. 1997. Morfodinâmica fluvial cenozoica no vale do Rio Paraopeba entre o Fecho do Funil e Juatuba, Minas Gerais. Departamento de Geografia, Universidade Federal de Minas Gerais, Minas Gerais, Dissertação (Mestrado em Geografia), 83p.

Medina, A.I., Dantas, M. E., Saadi, A. 2005. Geomorfologia. In: Projeto APA Sul RMBH Estudos do Meio Físico. Belo Horizonte: CPRM/SEMAD/CEMIG, 6.

Moreira, P.F. 1997. Depósitos cenozóicos e evolução morfodinâmica na bacia do Ribeirão 
Revista Brasileira de Geografia Física v.14, n.03 (2021) 1296-1311.

Serra Azul (médio Rio Paraopeba), Minas Gerais. Instituto de Geociências, Universidade Federal de Minas Gerais, Minas Gerais, Dissertação (Mestrado em Geografia), Belo Horizonte, $104 \mathrm{p}$.

Neves, M.A., Morales, N., Saad, A.R. 2005. Facies analysis of tertiary alluvial fan deposits in the Jundiaí region, São Paulo, southeastern Brazil. Journal of South American Earth Sciences [online] $19 . \quad$ Diponível: https://doi.org/10.1016/j.jsames.2005.06.008 Acesso jan. 2019.

Niu, G., Li, X., Zhao, Y., Yang, F. Li, S., Wand, Z. 2021. Magnetostratigraphy of a drilling core from the Baiyanghe alluvial fan at the westem margin of the Junggar Basin, NW China and its paleoenvironmental significance. Quatemary International [online] 589. Diponível: https://doi.org/10.1016/j.quaint.2021.02.016. Acesso maio 2021.

Nogueira, G., Effgen, J.F., Marchioro, E. 2020. Análise morfométrica e morfológica da Ilha da Trindade, Atlântico Sul, Brasil. Sociedade \& Natureza [online] 32. Disponível: https://doi.org/10.14393/SN-v32-2020-49647. Acesso maio 2021.

Oguchi, T. Oguchi, C.T. 2004. Late Quatemary rapid talus dissection and debris flow deposition on an alluvial fan in Syria. Catena [online] 55. Disponível: https://doi.org/10.1016/S03418162(03)00112-7. Acesso jan. 2020.

Oguchi, T., Saito, K., Kadomura, H., Grossman, M. 2001. Fluvial geomorphology and paleohydrology in Japan. Geomorphology [online] $39 . \quad$ Disponível: https://doi.org/10.1016/S0169-555X(01)000484 Acesso jan. 2019.

Peifer, D., Persano, C., Hurst, M., Bishop, P., Fabel, D. 2021. Growing topography due to contrasting rock types in a tectonically dead landscape. Earth Surface Dynamics [online] 9. Disponível: https://doi.org/10.5194/esurf-9167-2021. Acesso março 2021.

Plantz, J.B., Carelli, T. G., Borghi, L., Ramos R.R.C., Mello, C.L. 2019. Sequências Deposicionais da Porção Central do Complexo Deltaico do Rio Paraíba do Sul (RJ, Brasil). Anuário do Instituto de Geociências [online] 42. Disponível:

https://doi.org/10.11137/2019_3_254_273. Acesso maio 2021.

Ribeiro, L.M.L., Baltazar, O.F. 2013. Mapa Geológico Igarapéna Escala 1:100.000. Serviço Geológico do Brasil, CPRM, Belo Horizonte.
Rossi, P.G.G. 2008. Investigação da Influência da Estrutura Geológica na Evolução e Configuração da Geomorfologia da BordaLeste do Quadrilátero Ferrífero-MG. Departamento de Geografia, Universidade Federal de Minas Gerais, Belo Horizonte, Monografia (Graduação em Geografia) 69p.

Saadi, A. 1991. Ensaio sobre a morfotectônica de Minas Gerais. Belo Horizonte-MG, IGC/UFMG, Tese para admissão a cargo de Professor Titular, maio de 1991, 300 p.

Salgado, A., Braucher, R., Colin, F., Nalini jr, H., Varajão, A; Varajão, C. 2006. Denudation rates of the Quadrilátero Ferrífero (Minas Gerais, Brazil): Preliminary results from measurements of solute fluxes in rivers and in situ-produced cosmogenic 10Be. Journal of Geochemical Exploration [online] 88. Disponível: https://doi.org/10.1016/j.gexplo.2005.08.064 3. Acesso ag. 2019.

Salgado, A.A.R., Braucher R., Varajão C.A.C., Colin F., Varajão, A.F.D., Nalini Jr H. 2008. Relief evolution of the Quadrilátero Ferrífero (Minas Gerais, Brazil) by means of (10Be) cosmogenic nuclei. Zeitschrift fur Geomorphologie [online] 52. Disponível: https://dx.doi.org/10.1127/0372-

8854/2008/0052-0317. Acesso ag. 2020.

Salgado, A.A.R., Varajão, C., Colin F., Braucher, R., Varajão, A., Nalini Jr, H. 2007. Study of the erosion rates in the upper Maracujá Basin (Quadrilátero Ferrífero/MG, Brazil) by the in situ produced cosmogenic10Be method. Earth Surface Processes and Landforms 32: 905-911.

Santos, M. 1999. Serra da Mantiqueira e Planalto do Alto Rio Grande: a Bacia Terciária de Aiuruoca e evolução Morfotectônica. UniversidadeEstadual Paulista, SãoPaulo, Tese de Doutoramento em Geologia Regional, 134p.

Silveira, R.M.P., Silveira, C.T. 2020. Método Geomorfométrico para mapeamento de leques aluviais. Geosul [online] 35. Disponível: https://doi.org/10.5007/21775230.2020v35n76p66. Acesso maio 2021.

Sobreira, F.G. 2001. Susceptibilidade a processos geológicos e suas consequências na área urbana de Mariana, MG.Geo.br 1: 43-60.

Varajão, C.A.C., Salgado, A.A.R., Varajão, A.F.D.C., Braucher, R., Colin, F., Nalini JR., H.A. 2009. Estudo da evolução da paisagem do Quadrilátero Ferrífero (Minas Gerais, Brasil) por meio da mensuração das taxas de erosão (10Be) e da pedogênese. Revista Brasileira de Ciência do Solo [online] 33. Disponível: 
http://dx.doi.org/10.1590/S0100-

06832009000500032. Acesso jan. 2020.

Varajão, C.A.C. 1991. A questão da correlação das superfícies de erosão no Quadrilátero Ferrífero, Minas Gerais. Revista Brasileira de Geociências [online] 21.2 Disponível: http://ppegeo.igc.usp.br/index.php/rbg/article/v iew/11749. Acesso jun. 2020.

Vasconcellos, S.M., Kobiyama, M., Dagostin, F.S., Corseuil, C.W., Castiglio, V.S. 2021. Flood Hazard Mapping in Alluvial Fans with Computational Modeling. Water Resour Manage [online] 35. Disponível: https://link.springer.com/article/10.1007/s1126 9-021-02794-7. Acesso maio 2021.
Vasconcellos, S.M., Kobiyama, M. 2019. Análise do perigo de inundação nos leques aluviais da bacia do alto Rio Mampituba, RS/SC. In: XXII Congresso Brasileiro de Recursos Hídricos, 110.

Welivitiya, W.D.D.P., Willgoose G.R., Hancock G.R. 2020. Geomorphological evolution and sediment stratigraphy of numerically simulated alluvial fans. Earth Surface Process and landforms [online] 45. Disponível: https://doi.org/10.1002/esp.4872. Acesso maio 2021. 